\title{
Anti-cancer Effects of Azadirachta indica in Diethylnitrosamine-Induced Hepatocellular Carcinoma in Wistar Rats
}

\author{
Ricadonna Raissa, Wibi Riawan, Anna Safitri, Ma Asuncion Guiang Beltran, Aulanni’am \\ Aulanni’am
}

\begin{abstract}
Hepatocellular carcinoma $(\mathrm{HCC})$ is a primary liver cancer and has a high rate of mortality. Exploration of local herbal as a chemo-preventive drug has been conducted. This present study aimed to observe the anti-cancer effect of hydroethanolic extracts of Azadirachta indica both Indonesia (HEAII) and the Philippines (HEAIP) on diethylnitrosamine (DEN)-induced HCC on Wistar rat model. VEGF/FGF2/CD166/YAP were evaluated using immunohistochemistry. VEGF/FGF2/CD166/YAP were down-regulated in HCC treated with HEAII and HEAIP compare to that non-treatment HCC. Liver function (aminotransferase (AST) and aminotransferase (ALT) activities) was evaluated from serum. Value of AST and ALT were abnormal in the non-treatment HCC and normal in the HCC treated. These results indicated that both extracts were found to possess anti-cancer activity in HCC.
\end{abstract}

Keywords: hepatocelullar carcinoma; Azadirachta indica; cluster differential 166 (CD166); fibroblast growth factor 2(FGF-2); yes associated protein (YAP); vascular endothelial growth factor (VEGF)

\section{INTRODUCTION}

$\mathrm{H}$ epatocellular carcinoma (HCC) is a primary liver tumor and a major health issue in developing country. The prevalence of HCC is common cause of cancer-related death in Asia Pasific (Zhu et al., 2016). Treatment of HCC remains challenge, due to late diagnosis and short of therapeutic option. Systemic therapeutic as possible chemotherapy is Sorafenib but the efficiency of this drug is limited (Grazie $e t$ al., 2017). Therefore, discovering novel therapeutic targets and therapeutic strategies for HCC is still necessary.

Currently, available drugs are plant-based, turning out to be a crucial source of biological compound performing bio activities that can be exploited to produce medicine. Plant

Revised Manuscript Received on January 2, 2020.

* Correspondence Author

Ricadonna Raissa, Chemical Science Study Program, Faculty of Mathematics and Natural Science, Universitas Brawijaya, Malang, Indonesia. Email: donnabiochem@student.ub.ac.id.

Wibi Riawan, Departement of Biochemistry, Faculty of Medicine, Universitas Brawijaya, Malang, Indonesia

Anna Safitri, Departement of Chemistry, Faculty of Mathematics and Natural Science, Universitas Brawijaya, Malang, Indonesia. Email: annasafitri80@gmail.com

Ma Asuncion Guiang Beltran, College of Veterinary Medicine, Tarlac Agricultural University, Camiling, Tarlac, Philippines. Email: marizonbeltran@yahoo.com .

*Aulanni'am Aulanni'am, Departement of Biochemistry, Faculty of Veterinary Medicine, Universitas Brawijaya, Malang, Indonesia. Email: aulanib@ub.ac.id

contains diverse active ingredients which can be used as medicine for diseases such as cancer. Among the medicinal plants, one of the commonly found plants in tropical countries traditionally named Mimba (Azadirachta indica). In the Philippines, it is known as neem. A. indica is native plant to South Asia. A. indica was widely planted and naturalized in semiarid areas throughout Asia and Africa (Kumar and Navaratnam, 2013). As a medicinal plant, it has been reported as anti-parasitic, anti-inflammatory, and anti-diabetic. Moreover, $A$. indica extract has also anti-tumor activities (Paul et al., 2011).

One of threatening phenomenon in neoplasm is angiogenesis and metastasis. Angiogenesis is establishment process of making new blood vessel. It is a regular part of growth and healing; however it has a role as key player in the growth and metastasis of cancer. Restriction of angiogenesis is a substantial approach for cancer treatment and prevention. Numerous factors expressed when cancer-promoted angiogenesis are vascular endothelial growth factor (VEGF) and fibroblast growth factor-2 (FGF2). Angiogenesis is also essential for the propagatic and development of tumor metastasis (Folkman, 2002).

Metastatic tumor occurs because of the activation of cluster of differentiation 166 (CD166) and Yes-associated protein (YAP). Their activation promotes proliferation and metastasis. CD166 and YAP can be a potential prognostic marker in cancer malignancy. Previous study by Tang et al.,(2015) reports that CD166 and YAP are involved in hepatocarcinogenesis.

This research aimed to evaluate the anti-cancer effects of hydroethalonic extract $A$. indica in diethylnitrosamine inducing hepatocellular carcinoma in wistar rats through the expression of CD166/VEGF/FGF2/YAP using immunohistochemistry and liver function aminotransferase (AST)/aminotransferase (ALT) activities.

\section{MATERIALS AND METHODS}

\section{A. Chemicals}

Diethylnitrosamine (DEN) were obtained from Sigma Chemicals Co. (St. Louis, MO, USA). Sorafenib was brought from Dr. Soetomo Hospital, Surabaya. All other chemicals used for experiments were analytical grade. 


\section{B. Identification of Plant Material and Preparation of Azadirachta indica Extract}

A.indica were collected from the Madura Island, Indonesia and Camiling, Philippines on November 2018. Its leaves were dried under shadow, grinded and extracted by maceration with $80 \%$ ethanol at room temperature for 3 days. The extract was concentrated under controlled temperature and pressure $\left(50^{\circ} \mathrm{C}\right)$ in a rotary evaporator. The extract was a yellowish brown and was preserved in $4^{\circ} \mathrm{C}$.

\section{Experimental Animal}

Healthy male Wistar rats (Rattus norvegicus) were purchased from Institut Biosains, Malang. The animals were caged individually in controlled temperature $\left(25 \pm 2^{\circ} \mathrm{C}\right)$ with light cycle (12h dark/light). Rats were fed with pellet and water ad libitum. A total of 27 rats were divided into 3 groups, each group containing nine animals. This research procedure was approved by Institut Biosains, Universitas
Brawijaya, Indonesia. No. 1138-KEP-38.

\section{Immunohistochemistry}

Liver samples were processed in standard protocol of fixation, embedding, deparaffinization, labeling primary antibody (VEGF, FGF-2, YAP, and CD166) and secondary antibody, counterstaining.

\section{E. AST and ALT}

AST and ALT were collected from centrifuged blood. Centrifuge was performed by $3000 \mathrm{rpm}$ at room temperature for 10-15 minutes. Then, data was analyzed by One Way Anova statistical test and pass the Tukey test with a confidence of $95 \%$.

\section{RESULT AND DISCUSSION}

The results were shown in (Figure 1. and Tabel 1). All values are mean \pm standard deviation. Data are analyzed by One-way ANOVA followed by Tukey's post hoc method of analysis, where $* \mathrm{p}<0$
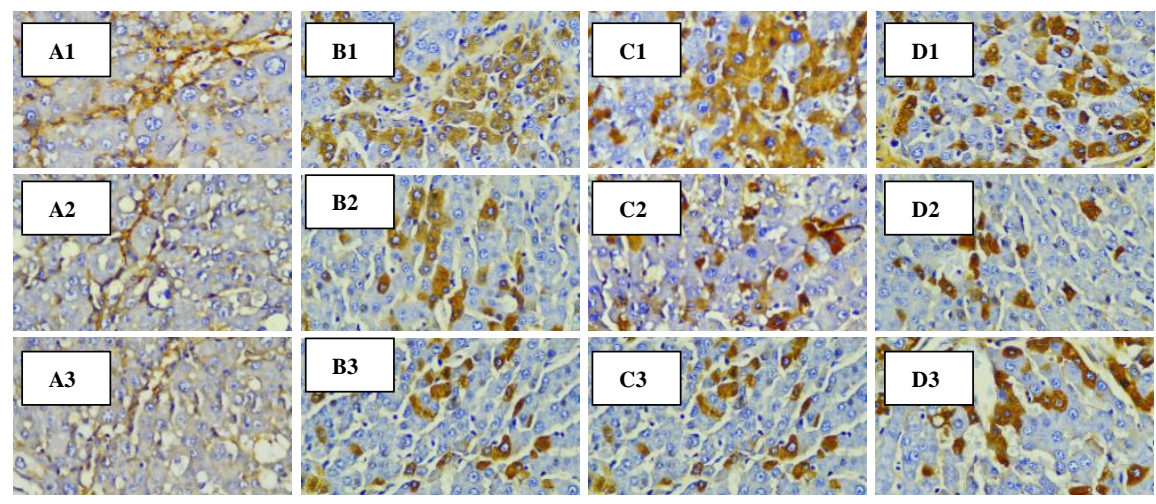

Figure 1. Expression of A (VEGF), B (FGF2), C (CD166), D (YAP) in liver tissues of rats by immunohistochemistry. Visualized by an optical microscope (x400). Group 1 (non-treated HCC), Group 2 (non-treated HCC with HEAII), Group 3 (non-treated HCC with HEAII)

Table 1. Activity of AST and ALT

\begin{tabular}{|c|c|c|}
\hline Groups & $\begin{array}{c}\text { AST } \\
\text { (average } \pm \text { SD) }\end{array}$ & $\begin{array}{c}\text { ALT } \\
\text { (average } \pm \text { SD) }\end{array}$ \\
\hline Non-Treatment (IU/L) & $250.5555^{\mathrm{a}} \pm 15.28162$ & $83.4444^{\mathrm{a}} \pm 5.7288$ \\
\hline HEAII Treatment (IU/L) & $138.6667^{\mathrm{b}} \pm 37.62978$ & $43.0000^{\mathrm{b}} \pm 10.53565$ \\
\hline HEAIP Treatment (IU/L) & $142.7778^{\mathrm{b}} \pm 33.7074$ & $45.3333^{\mathrm{b}} \pm 10.35616$ \\
\hline
\end{tabular}

\section{DISCUSSION}

Previous studies suggest that impaired liver function reflects tumor induced liver damage (Huang et al., 2006). Therefore, we explored the relationships between expression of VEGF, FGF2, CD166, and YAP and liver function test parameters after treatment with HEAII and HEAIF damage induced by HCC after treatment with HEAII and HEAIF.

The present study was aimed to observe the anti-cancer effect of hydroethanolic extracts of Azadirachta indica both Indonesia (HEAII) and the Philippines (HEAIP) on diethylnitrosamine (DEN)-induced HCC on Wistar rat model. They were tested for their anticancer effect by imunoexpression of VEGF/FGF2/CD166/YAP and level of AST/ALT level. VEGF/FGF2/CD166/YAP were evaluated using immunohistochemistry. VEGF (A), FGF2 (B), CD166 (C), YAP (D) were down-regulated in HCC treated both HEAII (A2, B2, C2, D2) and HEAIP (A3, B3, C3, D3) compare to those non-treatment $\mathrm{HCC}(\mathrm{A} 1, \mathrm{~B} 1, \mathrm{C} 1, \mathrm{D} 1)$.

VEGF and FGF 2 in treatment group is decrease than non treatment group. As we know, VEGF plays as a key pivotal roles in regulating normal and abnormal angiogenesis (Niu and Chen, 2010). VEGF expression increase by FGF-2. FGF-2 is a powerful inducer of angiogenesis and differentiation in numerous organs (Seghezzi et al., 1998). Menchanism of VEGF-FGF2 induce angiogenesis is through intracelullar menchanism (Seghezzi et al., 1998). HCC is a typical hyper vascular tumor; many angiogenic factors have been studied in this cancer (Niu and Chen, 2010). This study showed that HEAII and HEAIP treatment decreased VEGF and FGF2, indicating that the formation tumor angiogenesis decreased because FGF-2 production upregulates VEGF expression. Therefore, it may be said that the anti-angiogenic activity of $A$. indica might correspond to phytochemicals such as terpenoids and flavonoids present in large amount in the HEAII and HEAIP. 
CD166 has been indicated to participate in the metastatic cascade of cancer cells. CD166 plays an important role in many biological activities, including $\mathrm{T}$-cell activation and proliferation, angiogenesis, hematopoiesis (Ni et al., 2013). CD166 was linked to YAP in liver cancer, and YAP is over expressed in $62 \%$ of $\mathrm{HCC}$ patients. Membrane protein CD166 increase YAP to take carcinogenic in HCC (Ma et al., 2014). YAP are nuclear localized in aggressive cancers. Thus, co expression of CD166 and YAP could be prognostic in cancer (Zhang et al., 2018). This study showed CD166/YAP down regulated HCC treated with HEAII and HEAIP compare to that HCC non-treatment. In Figure I, expression of CD166 and YAP decrease in liver tissue of both HCC treated groups. This indicating that both $A$. indica extract has anti metastatic in HCC.

Liver function (aminotransferase (AST) and aminotransferase (ALT) activities) was evaluated from serum. Hepatocyte damage due to hepatocellular carcinoma arising from the emergence of necrotic hepatocyte products in the circulatory system to form aspartate aminotransferase (ALT). Increased activity of the ALT enzyme when liver tissue is damaged allows karmaous plasma membrane damage resulting in protein leakage. This observation looked at the effect of HEAII and HEAIP on the activity of AST and ALT enzymes in the liver of hepatocellular carcinoma rats obtained compared with non treated HCC.

Analysis of AST and ALT enzyme activity was carried out quantitatively by measuring the absorbance of AST and ALT enzyme activity products. Based on the results obtained continued with the One Way Anova statistical test and pass the Tukey test with a confidence of $95 \%$ showing the therapeutic choice of AST and ALT enzyme activity in the liver. Tukey test results showed no difference between therapies.

In this study, the high activity of AST and ALT before the administration of HEAII and HEAIP therapy showed that there was damage to the liver tissue. ALT and AST are produced by malignant and non-malignant cells. Compared to normal cells, AST and ALT activity increases after hepatic neoplasia. AST and ALT are found in serum proportional to the amount of cell damage. Most cancer cells produce ATP through glycolysis in aerobic conditions rather than through the tricarboxylic acid cycle. Glycolysis is needed in cancer cells to produce ATP and anabolic precursors needed for survival, growth, and invasion. The aspartate aminotransferase enzyme catalyzes the conversion of aspartate and alpha-ketoglutarate to oxaloacetate and glutamate. (Washington and Hoosier, 2012), in which glutamate functions as a precursor to provide carbon and nitrogen for the biosynthesis of metabolites involved in cancer survival and proliferation. Glutamate has been shown to maintain the TCA cycle and increase gluconeogenesis to increase cancer cell growth. AST functions with malate dehydrogenase to transfer electrons from nicotinamide adenine dinucleotide (NADH) across the inner mitochondrial membrane, which is closely related to glycolysis (Shen et al., 2014; Stocken et al., 2008). Thus, AST can be associated with the prognosis of hepatocellular carcinoma cancer

\section{CONCLUSION}

In conclusion, these findings suggest that HEAII and HEAIP inhibits migration, invasion, angiogenesis response of HCC and increase liver function toward normal. Our study indicates the importance for further validation of the anti-angiogenic potential in pre-clinical models and in clinical trials, for successful neem treatment into the clinic to prevent tumor progression.

\section{ACKNOWLEDGMENT}

This study was supported by grants the PMDSU Programs. The authors are grateful for financial support from the Republic of Indonesia's Ministry of Research, Technology and Higher Education.

\section{REFERENCES}

1. Folkman, J., 2002. Role of angiogenesis in tumor growth and metastasis Semin. Oncol. 29, 15-18. https://doi.org/10.1053/sonc.2002.37263

2. Grazie, M.L., Biagini, M.R., Mirko, T., Simone, P., Andrea, G., 2017. Chemotherapy HCC.pdf.

3. Huang, X.-J., Choi, Y.-K., Im, H.-S., Yarimaga, O., Yoon, E., Kim, H.-S., 2006. Aspartate Aminotransferase (AST/GOT) and Alanine Aminotransferase (ALT/GPT) Detection Techniques. Sensors 6, 756-782. https://doi.org/10.3390/s6070756

4. Kumar, V.S., Navaratnam, V., 2013. Neem (Azadirachta indica) Prehistory to contemporary medicinal uses to humankind. Asian Pac. J. Trop. Biomed. 3, 505-514 https://doi.org/10.1016/S2221-1691(13)60105-7

5. Ma, L., Wang, J., Lin, J., Pan, Q., Yu, Y., Sun, F., 2014. Cluster of Differentiation 166 (CD166) Regulated by Phosphatidylinositide 3-Kinase (PI3K)/AKT Signaling to Exert Its Anti-apoptotic Role via Yes-associated Protein (YAP) in Liver Cancer. J. Biol. Chem. 289, 6921-6933. https://doi.org/10.1074/jbc.M113.524819

6. Ni, C., Zhang, Z., Zhu, X., Liu, Y., Qu, D., Wu, P., Huang, J., Xu, A., 2013. Prognostic Value of CD166 Expression in Cancers of the Digestive System: A Systematic Review and Meta-Analysis. PLoS ONE 8, e70958. https://doi.org/10.1371/journal.pone.0070958

7. Niu, G., Chen, X., 2010. Vascular Endothelial Growth Factor as an Anti-Angiogenic Target for Cancer Therapy. Curr. Drug Targets 11, 1000-1017. https://doi.org/10.2174/138945010791591395

8. Paul, R., Prasad, M., Sah, N.K., 2011. Anticancer biology of Azadirachta indica L (neem): A mini review. Cancer Biol. Ther. 12, 467-476. https://doi.org/10.4161/cbt.12.6.16850

9. Seghezzi, G., Patel, S., Ren, C.J., Gualandris, A., Pintucci, G., Robbins, E.S., Shapiro, R.L., Galloway, A.C., Rifkin, D.B., Mignatti, P., 1998 Fibroblast Growth Factor-2 (FGF-2) Induces Vascular Endothelial Growth Factor (VEGF) Expression in the Endothelial Cells of Forming Capillaries: An Autocrine Mechanism Contributing to Angiogenesis. J. Cell Biol. 141, 1659-1673. https://doi.org/10.1083/jcb.141.7.1659

10. Stocken, D.D., Hassan, A.B., Altman, D.G., Billingham, L.J., Bramhall, S.R., Johnson, P.J., Freemantle, N., 2008. Modelling prognostic factors in advanced pancreatic cancer. Br. J. Cancer 99, 883-893. https://doi.org/10.1038/sj.bjc.6604568

11. Shen, S.-L., Fu, S.-J., Chen, B., Kuang, M., Li, S.-Q., Hua, Y.-P., Liang, L.-J., Guo, P., Hao, Y., Peng, B.-G., 2014. Preoperative Aspartate Aminotransferase to Platelet Ratio is an Independent Prognostic Factor for Hepatitis B-Induced Hepatocellular Carcinoma After Hepatic Resection. Ann. Surg. Oncol. 21, 3802-3809. https://doi.org/10.1245/s10434-014-3771-X

12. Tang, X., Chen, X., Xu, Y., Qiao, Y., Zhang, X., Wang, Y., Guan, Y., Sun, F., Wang, J., 2015. CD166 positively regulates MCAM via inhibition to ubiquitin E3 ligases Smurfl and $\beta$ TrCP through PI3K/AKT and c-Raf/MEK/ERK signaling in Bel-7402 hepatocellular carcinoma cells. $\begin{array}{lll}\text { Cell. } & \text { Signal. } & \text { 27, }\end{array}$ https://doi.org/10.1016/j.cellsig.2015.05.006

13. Zhang, X., Abdelrahman, A., Vollmar, B., Zechner, D., 2018. The Ambivalent Function of YAP in Apoptosis and Cancer. Int. J. Mol. Sci. 19, 3770. https://doi.org/10.3390/ijms19123770

14. Zhu, R.X., Seto, W.-K., Lai, C.-L., Yuen, M.-F., 2016. Epidemiology of Hepatocellular Carcinoma in the Asia-Pacific Region. Gut Liver 10. https://doi.org/10.5009/gn115257 
15. Washington, I. M., \& Van Hoosier, G. (2012). Clinical Biochemistry and Hematology. The Laboratory Rabbit, Guinea Pig, Hamster, and Other Rodents, 57-116. doi:10.1016/b978-0-12-380920-9.00003-1

\section{AUTHOR PROFILE}

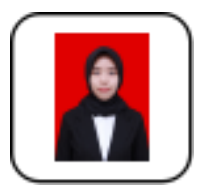

Drh. Ricadonna Raissa, M.Si, is a doctoral biochemistry student of Universitas Brawijaya. She is also a member of Indonesia veterinary associated. She researches in cancer treatment from herbal. She published one research article.

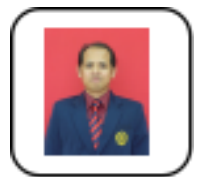

Wibi Riawan, S.Si, M.Biomed, is a biochemis researcher at the Department of Biochemistry and Biomolecular, Faculty of Medicine, Universitas Brawijaya. He has research experience epigenetics on cancer. He has also published more than 60 peer review research article.

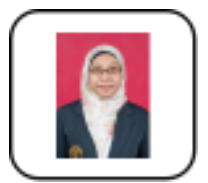

Anna Safitri, S.Si, M.Sc, Ph.D, is a biochemist researcher at the Department of Chemistry, Faculty of Mathematic and Natural Science. She is also a secretary of study center SIMONAGENES. Anna Safitri, Ph.D's workhas been published in medical, nutrigenomic study and environment safety

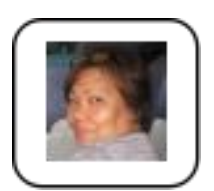

Prof. Ma Asuncion Guiang Beltran, DVM, MS, Ph.D is a researcher in animal science at College of Veterinary Medicine, Tarlac University. She has published more than 60 peer review research articles. Prof. Beltran's work has been published in animal science, reproductive artificial and biomolecular.

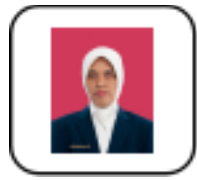

Prof. Aulanni'am, drh, DES, is a biochemist researcher at Department of Chemistry, Faculty of Mathematic and Natural Science. She published more than 200 peer review research article, 4 books and 8 intellectual property rights. She researches in diabetic, thyrod, animal reproductive disease and cancer. Prof. Aulanni'am's work has been published in Turkish Journal of Immunology, International Journal of Pharm tech Research, International Journal of Pharmacetical and Clinical Research. 